\title{
Table of Contents Entry
}

Acid catalyst promotes transmethylation in anisole decomposition through dual electrophilic attack mechanism, lowering intrinsic energy barriers by most $60 \mathrm{kcal} / \mathrm{mol}$.

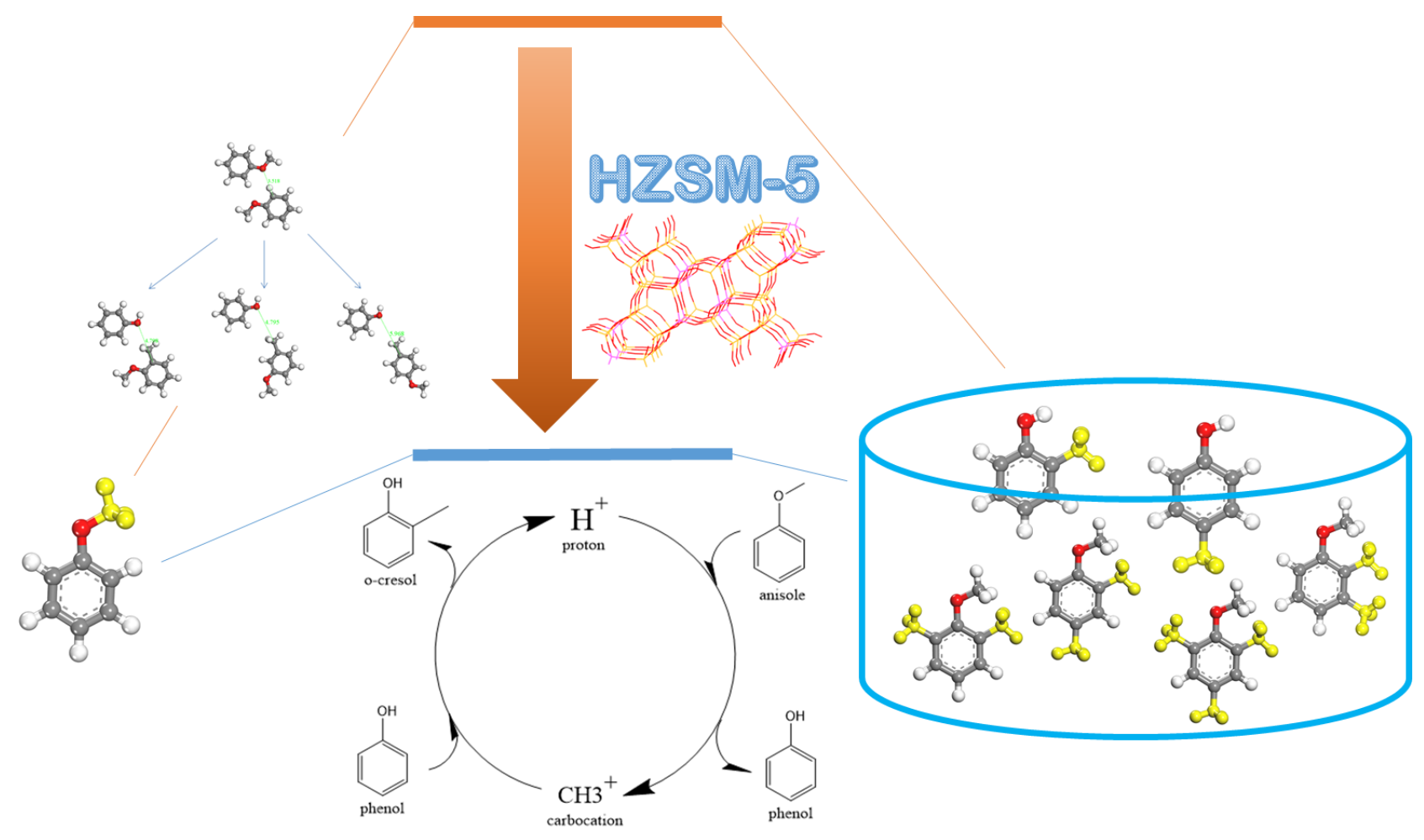




\section{Mechanism of transmethylation in anisole decomposition over Brønsted acid sites: Density} Functional Theory (DFT) study

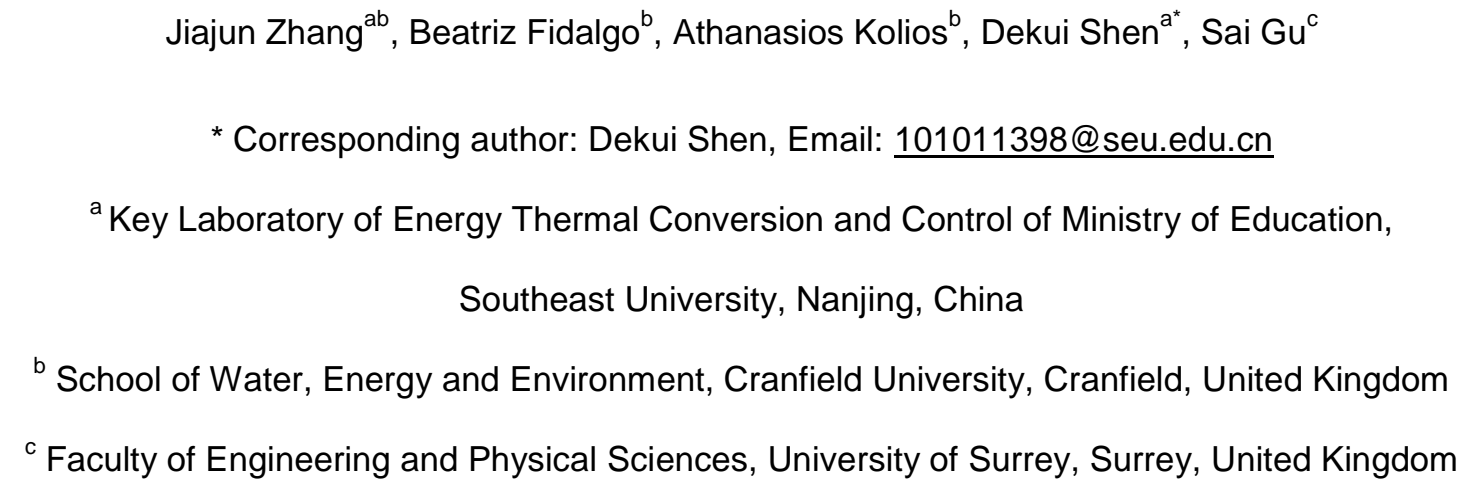
transmethylation, as the initial stage of the catalytic and non-catalytic anisole decomposition, were investigated by Density Functional Theory (DFT). Molecule analyses indicated that methyl free radical transfer happened in the absence of catalyst, and the catalytic transmethylation over Brønsted acid sites was considered based on the dual electrophilic attack mechanism with protonation and carbocation substitution respectively. Reactions modelling for the formation of methyl-contained compounds in both non-catalytic and catalytic anisole decomposition indicated that the energy barriers were significantly decreased in the presence of catalyst by $60 \mathrm{kcal} / \mathrm{mol}$ at the most in the case of o-cresol. The results also revealed that the intrinsic transmethylation orientation preferred the ortho- and para-positions on the acceptor compounds contained oxygen-rich substituents due to its large electronegativity, and the lowest energy barrier was observed in the case of transmethylation towards the para-position of the cresol molecule $(54.1 \mathrm{kcal} / \mathrm{mol})$.

Key words: lignin; catalytic decomposition; model compound; modelling; phenolic compounds; substituent

\section{Introduction}

Lignin is an abundant aromatic-rich bio-resource; approximately 63 million tones are extracted annually mainly from the pulp and paper industry ${ }^{1,2}$. The fast pyrolysis of lignin has been investigated since the late 1970s, and is accepted as a feasible and viable route to convert 
lignin into value added fuel additives ${ }^{3-5}$. However, the primary bio-oil produced from fast pyrolysis cannot be directly used in fuel applications. This is because of its inadequate properties, such as acidity, low calorific value, and low stability, which are a consequence of its high oxygen content in composition. The effective removal of the oxygen by catalytic upgrading is therefore crucial for making the bio-oil compatible with the existing fossil fuel infrastructure and for widening its use ${ }^{6,7}$. Catalytic cracking of bio-oil is one of the conversion routes usually suggested for deoxygenation, and zeolites with dispersed Brønsted acid sites, such as HZSM-5, have been proven as suitable catalysts for this process ${ }^{8-11}$.

The methoxy group is an oxygen containing functional group which abundantly exists in components present in the bio-oil obtained from the fast pyrolysis of lignin, such as anisole, guaiacol, syringol and their derivatives ${ }^{12}$. Understanding the reactivity of the methoxy group is required to properly assess the complete catalytic upgrading process of these lignin-derived aromatic compounds. Anisole is often used as a model compound to investigate the reactivity of lignin-derived compounds containing the methoxy functional group, because this is the only functional group present in the molecule ${ }^{13}$. Transmethylation reaction has been observed to be the primary reaction taking place in anisole decomposition, leading to the prominent production of phenolic compounds ${ }^{14-18}$.

Catalytic transmethylation over acid sites has been reported for phenol alkylation in the presence of methanol ${ }^{19-23}$. A few authors have described the transmethylation in the decomposition of anisole over acid sites consisting of isomerization, dealkylation, and intermolecular methyl transfer ${ }^{24,25}$. However, available literature mainly focused on the general study of pathways and kinetic parameters for the transmethylation reactions, with little details on catalysis mechanisms despite their importance to understand the entire catalytic process ${ }^{26}$. Although it is widely accepted that Brønsted acid sites play a dominant role in anisole decomposition ${ }^{14,19,24}$, the precise mechanism for transmethylation over the acid sites is still controversial. Different, and sometimes hardly consistent, reaction pathways and mechanisms have been proposed for explaining the same chemical process in previous studies ${ }^{19-23}$. This might attributed to that transition state is key to understanding chemical reaction mechanism, but it is extremely unstable and hard to capture by means of experimental studies ${ }^{27}$. Wang et al. ${ }^{16}$ have proposed hydrolysis as the first stage of the 
anisole conversion, with little interaction of the acid sites, followed by the alkylation of phenol with methanol. Thilakaratne et al. ${ }^{28}$ proposed the transmethylation mechanism based on the formation of a methenium ion during anisole decomposition on the Brønsted acid site. There has been other study suggesting the formation of a methyl carbocation directly by the methyl group in the anisole molecule ${ }^{14,24,25,28,29}$, nevertheless, the studies have seldom addressed how the carbocation is formed and to what extent it affects the transmethylation reaction. In most previous studies, further evidence to prove the proposed mechanism regarding the transmethylation, or to evaluate the reactions based on the mechanism were not provided.

Despite experimental results being highly valuable to understand the overall reaction and products distribution at a macroscopic level, they present limitations in unravelling the reaction mechanism at molecular level. Density Functional Theory (DFT) modelling is based on the calculation of electrons interactions, and has been widely used as a systematic and convincing approach in explaining molecular properties and mechanisms for many reactions 30-34. Compared to experimental approach, DFT calculation can provide intrinsic information of reactions regarding to detailed interaction between molecules and acid site, independently of the very short life span of the transition states, radicals and ions existing in the reactions. The microscale modelling of catalysis by DFT can also disregard complex impacts of macroscale factors (e.g. framework effects) and allows focusing on the reaction regarding its intrinsic properties. However, DFT calculation for transmethylation and related reactions has little been reported in the literature.

The aim of this work is to investigate by means of DFT modelling the mechanism of transmethylation as a primary reaction of the non-catalytic and catalytic decomposition of anisole, and to identify the effects of Brønsted acid sites on transmethylation. Compounds such as phenol, benzene, toluene, anisole, cresol, xylenol and tri-methyl phenol were investigated. The transfer orientation preference of the electrophilic substituents on relevant molecules was also studied. In addition, various possible reaction pathways of the transmethylation reaction were evaluated to address energy barriers during formation of major product compounds. 


\section{Computational method}

The first-principles density functional theory plus dispersion (DFT-D) calculations were implemented in the $\mathrm{DMol}^{3}$ module available in Materials Studio 2016 from BIOVIA ${ }^{35,36}$. The double numerical plus polarization (DNP) basis set was used to calculate the valence orbital of all the atoms, including a polarization p-function on all hydrogen atoms. The numerical basis sets in $\mathrm{DMol}^{3}$ minimize or even eliminate basis set superposition error (BSSE), in contrast to Gaussian basis sets, in which BSSE can be a serious problem ${ }^{37,38}$. Calculations used the generalized gradient corrected approximation (GGA) ${ }^{39}$ treated by the Perdew-Burke-Ernzerhof (PBE) exchange-correlation potential with long-range dispersion correction via Grimme's scheme ${ }^{40}$. The self-consistent field (SCF) procedure was used with a convergence threshold of $10^{-6}$ au on the energy and electron density. Geometry optimizations were performed with a convergence threshold of $0.002 \mathrm{Ha} / \AA$ on the gradient, $0.005 \AA$ on displacements, and $10^{-5} \mathrm{Ha}$ on the energy. The real-space global cut-off radius was set to $5 \AA$. In this study, no symmetry constraints were used for any cluster models. The transition state was completely determined by the LST/QST method, and confirmed by the unique imaginary frequency as shown in Table S1 in the supplementary information and Intrinsic reaction coordinate (IRC) calculation. Milliken charges were assigned to each bond to address the bond order, and Hirshfeld charges were assigned to each atom for the function selected as the Fukui field ${ }^{41}$. Radical Fukui analysis was applied to the phenol molecule to establish its reactivity to free radical attack in non-catalytic reactions. Electrophilic Fukui analysis was applied to anisole and phenol molecules to determine their reactivity to carbocation attack in catalytic reactions. The same computation condition was applied for both catalytic and noncatalytic modellings; in the case of catalytic reactions modelling, mainly Brønsted acid was considered. The initial configuration of the ZSM-5 catalysts was obtained from the siliceous ZSM-5 crystal, and an 8T model was used to simulate the performance of a Brønsted acid site ${ }^{31,32}$. The energy barrier for transmethylation reaction was determined by the difference between the transition state and reactant energies. The relative energy of the transition state and product was defined as the energy difference with the reactant respectively. All the energies were calculated at $\mathrm{OK}$ to investigate the intrinsic reactions of transmethylation. 


\section{Results and discussions}

\subsection{Mechanism for transmethylation in anisole decomposition}

119 The weakest bond in anisole molecule was observed for $\mathrm{C}_{\mathrm{SP}}{ }^{3}-\mathrm{O}$ (as shown in Fig S2(a), Bond 120 ID C8-O7), indicating that both the non-catalytic and catalytic thermal decomposition of 121 anisole is preferably initiated at this site ${ }^{29}$.

122 In the case of the non-catalytic decomposition of anisole, the molecule is subsequently 123 cracked into free radicals, with a methyl radical being formed, which substitutes the hydrogen 124 molecule on a phenol molecule to produce cresols ${ }^{29}$, and the free radical substitutions are 125 more likely to occur at the ortho-position and para-position of the phenol molecule (based on 126 radical Fukui analysis (Fukui (0)) to phenol molecule, shown in Fig S3(a)). A previous 127 experimental work by the group of $\mathrm{J}$. Zhang et al ${ }^{42}$ concluded the preferential formation of 128 cresols at temperatures lower than $650^{\circ} \mathrm{C}$ during the non-catalytic decomposition of anisole. It 129 should be noticed that due to there is no obvious intermediate compound existing in the non130 catalytic transmethylation reactions, they are more likely to occur as one step reactions.

131 In the case of the catalytic decomposition of anisole over Brønsted acid sites, it has been 132 largely recognized that the transmethylation reaction is induced by a proton that dissociates 133 from the acid site and launches an electrophilic attack on the reactant ${ }^{14,43-46}$. The 134 transmethylation mechanism is proposed to proceed through carbocation transfers in the 135 case of catalytic decomposition of anisole, as shown in Fig 1.

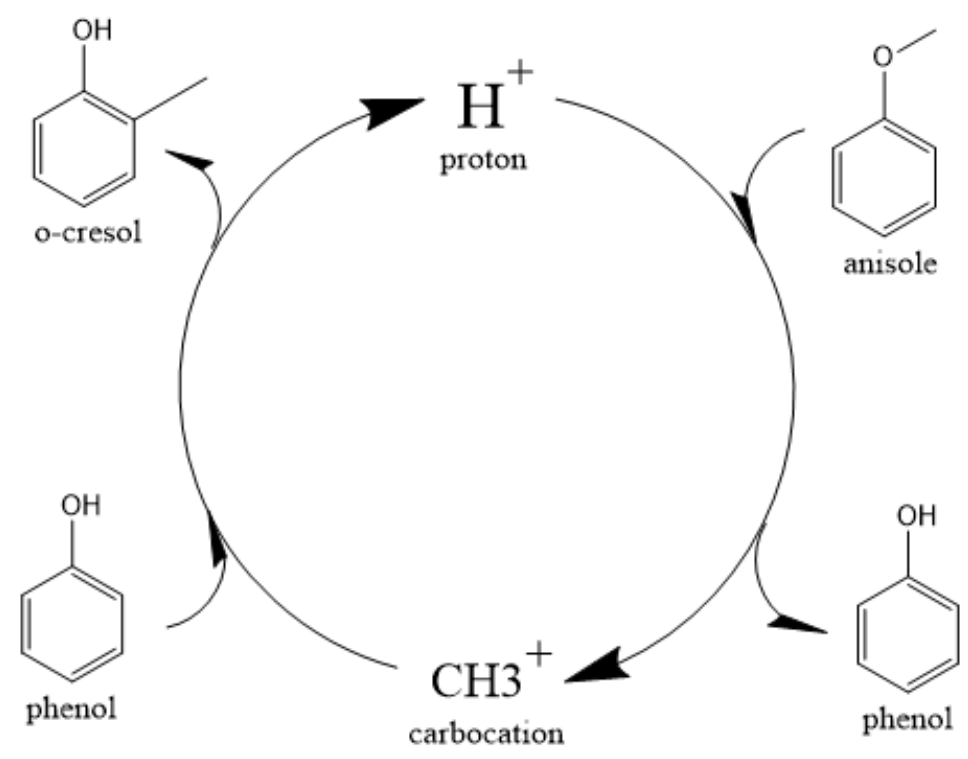


138 The catalytic process of transmethylation can be divided into two steps. The first step consists

139 of the methyl group cleavage in the anisole molecule; an initial electrophilic attack is launched

140 by the proton dissociated from the catalyst acid site to the $O$ atom (based on the electrophilic

141 Fukui (Fukui (-)) analysis to anisole molecule, as shown in Fig S2(b)), and the methyl

142 carbocation is released. A second electrophilic attack is launched by the methyl carbocation

143 group; the group is likely to substitute the hydrogen atom at the 0 - and p-positions on the 144 phenol ring (based on the electrophilic Fukui analysis (Fukui (-)) to phenol molecule, as 145 shown in Fig S3(b)). The displaced free proton simultaneously interacts with the catalyst to 146 recover the Brønsted acid site and maintain the catalytic activity throughout the reaction. 147 Transition state compounds normally exist for a very short time due to instability; however, the 148 methyl carbocation attached to the active site during the transmethylation process is a 149 relatively stable structure with zero valent. Consequently, it can be considered as an 150 intermediate compound, rather than a transition state compound, therefore it is possible to 151 consider the methyl carbocation cleavage and the carbocation substitution reactions as 152 separate steps in the catalytic transmethylation. The mechanism described in Fig 1 shows 153 that the use of Brønsted acid catalyst replaces the one-step reaction of direct methyl free 154 radical transfer observed for the non-catalytic reaction by a two-step process [25]. The 155 mechanism also shows constant maintenance of acid sites in the catalyst by proton recovery 156 throughout the reaction. Further reaction modelling was carried out considering the 157 mechanism proposed here.

158 It is worth noting that in both non-catalytic and catalytic decomposition of anisole, the methyl 159 group transfers not only to phenol but also to other compounds such as benzene, toluene, 160 and even non-decomposed anisole present in the reaction media ${ }^{42}$. All the transmethylation 161 processes are initiated from methyl cleavage.

\section{$162 \quad 3.2$ Modelling of non-catalytic and catalytic transmethylation of anisole to phenol}

163 The transmethylation reactions with a phenol molecule in the non-catalytic and catalytic 164 decomposition of anisole were modelled. Both non-catalytic and catalytic transmethylation models were built by locating equidistantly the reactant molecules (about $3 \AA$ ) to minimize any possible position-related errors. The catalytic transmethylation was modelled based on the 
dual electrophilic attack mechanism proposed in Fig 1, considering the system containing methyl carbocation on the acid site as the intermediate compound (see Fig 2). The modelling was implemented in two stages: methyl carbocation cleavage from anisole over the catalyst active site, and transfer of the carbocation to the surrounding molecules. The transition states for both stages are denoted as TS1 and TS2 respectively. The non-catalytic transmethylation model was built according to the free radical mechanism, and the transition state of the reaction is denoted as TS. The cleavage energy of the carbocation from the anisole molecule (for TS1) and the energy barriers for the methyl carbocation transfer to ortho-, meta-, and para-positions of phenol (for TS2) during the catalytic transmethylation of anisole to form cresol via phenol, as predicted by the model, are shown in Fig 3. The transition state (TS) and corresponding energy barriers for the non-catalytic transmethylation of anisole to form $\mathrm{n}$ cresol are shown for comparison.

As can be seen in Fig 3, the transmethylation to the ortho-position of phenol presented a lower energy barrier than the meta-position and para-position transfers both in non-catalytic and catalytic decomposition. This result indicates that ortho-position transmethylation is more likely to occur to the phenol molecule, which agrees with the experimental observations found elsewhere ${ }^{42}$. In short, experiments showed that o-cresol was formed at a lower temperature $\left(550^{\circ} \mathrm{C}\right)$ than $\mathrm{p}$-cresol $\left(600^{\circ} \mathrm{C}\right)$ in non-catalytic anisole decomposition, and most multi-methyl phenolic compounds presented the ortho-position occupied by a methyl group in the catalytic anisole decomposition ${ }^{42}$. In addition, the model pointed to the highest energy barrier for the meta-position transfer. This is in agreement with experimental results, which exhibited no evidence of m-cresol formation ${ }^{42}$. However, it should be noted that the results in this study show the intrinsic properties of the reaction, and the experimental yields obtained are normally subjected to other effects, such as the framework topology effects of different zeolites. For example, shape selectivity of microporous zeolites plays a key role in the catalyst promoting the production of para-cresol ${ }^{25}$. 


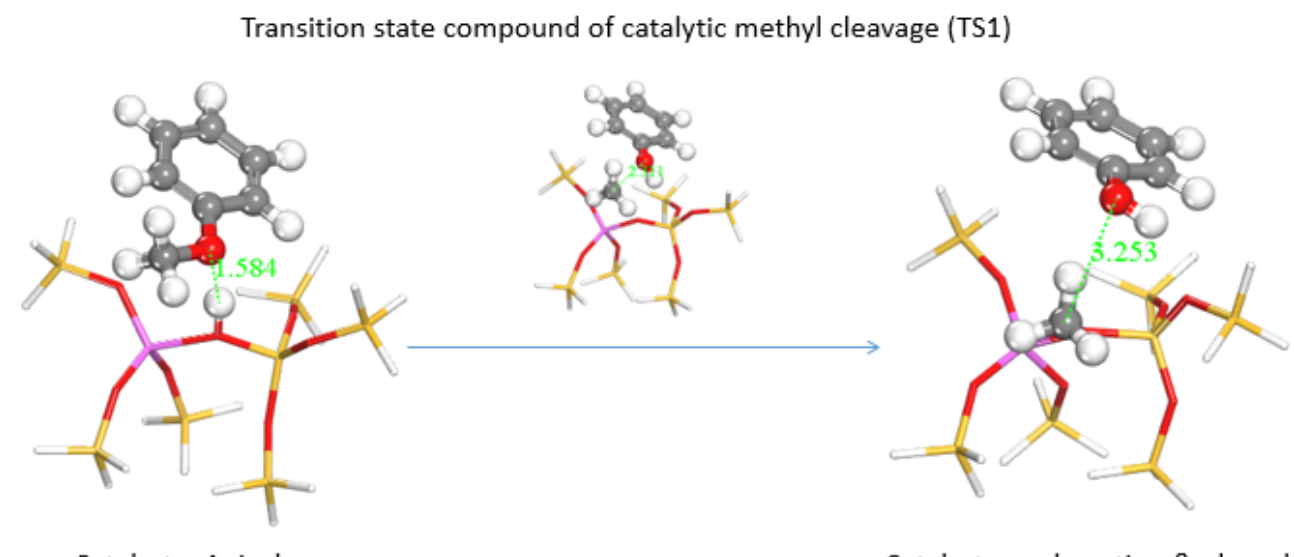

193

194

195

196

197

198

199

200

201

202

203

204

205

206

207

208

209
Catalyst + Anisole

(a)

Transition state compound of carbocation transfer (TS2)

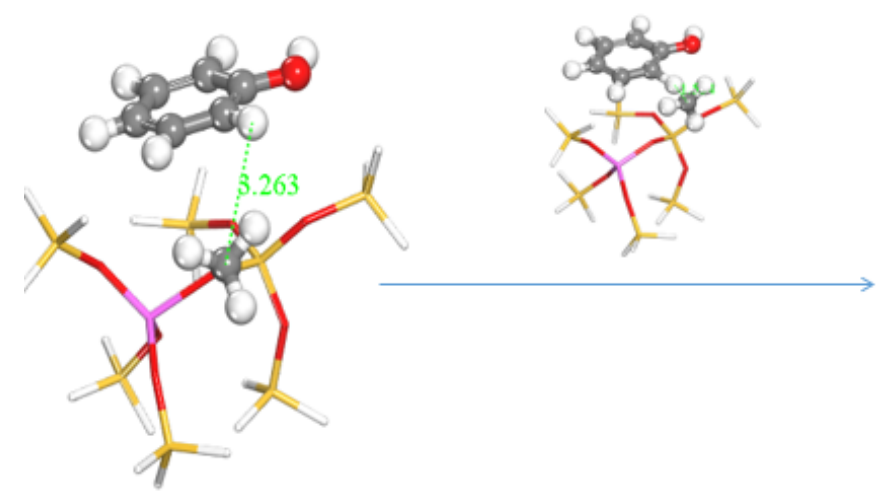

Catalyst + Carbocation \& phenol

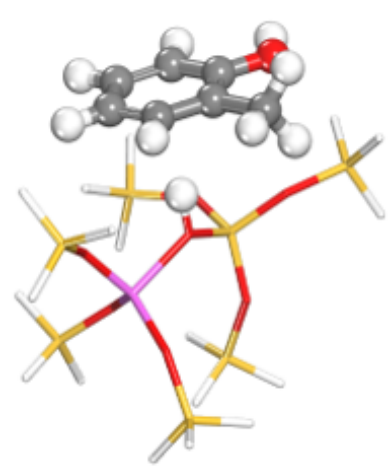

Catalyst + o-cresol

(b)

Fig 2. (a) CSP3-O bond (C8-O7) cleavage and carbocation formation; (b) Methyl carbocation transfer to ortho-position of phenol (transfers to meta- and para-positions are not shown here). Atoms are colored as follows: carbon atom (grey), hydrogen atom (light grey), oxygen atom (red), silica atom (yellow) and aluminum atom (pink).

The model also predicted that the energy barrier for the methyl cleavage in the presence of the catalyst was $66.4 \mathrm{kcal} / \mathrm{mol}$, which is much lower than the energy barrier values of the noncatalytic process. Moreover, compared to the non-catalytic process, the energy barrier for catalytic transmethylation to ortho-position decreased from $105.5 \mathrm{kcal} / \mathrm{mol}$ to $60.7 \mathrm{kcal} / \mathrm{mol}$, and those for para- and meta-positions dropped from $107.3 \mathrm{kcal} / \mathrm{mol}$ to $66.1 \mathrm{kcal} / \mathrm{mol}$ and from $118.0 \mathrm{kcal} / \mathrm{mol}$ to $67.2 \mathrm{kcal} / \mathrm{mol}$ respectively. These results are also in line with experimental data which showed that a lower temperature (approximately by $150^{\circ} \mathrm{C}$ ) was required to achieve a similar conversion ratio during the catalytic decomposition of anisole compared to non-catalytic decomposition ${ }^{42}$. 


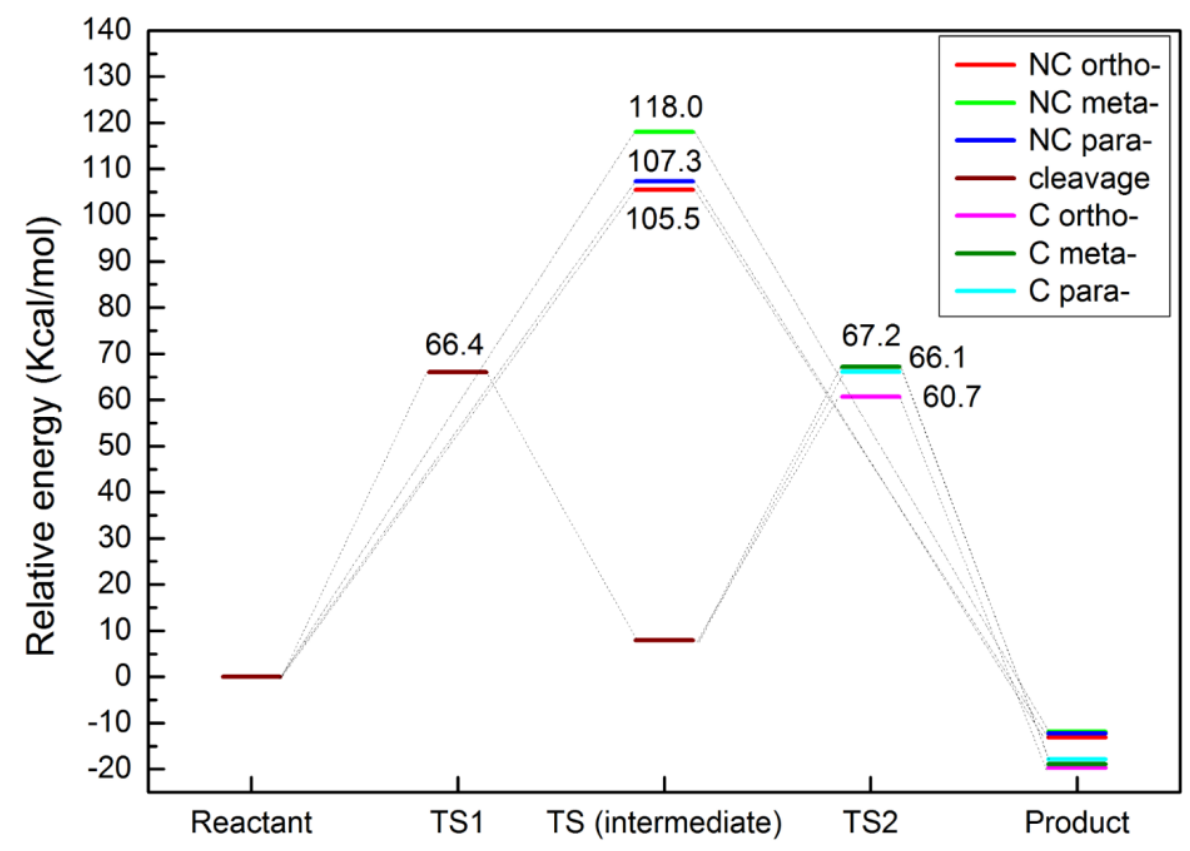

Fig 3. Energy barriers for transmethylation reactions of anisole to cresol (via phenol). (C denotes to catalytic transmethylation; NC denotes to non-catalytic transmethylation)

\subsection{Modelling of non-catalytic and catalytic transmethylation of anisole to other acceptor molecules}

Besides the cresol, the transmethylation process also gives rise to other methyl substituted compounds ${ }^{42}$. Therefore, transmethylation reactions with other acceptor molecules were modelled to assess the reactivity of these intermediate compounds, and the selectivity of the resulting products. The formation of toluene, methyl anisole, xylene, xylenol, and trimethylphenol due to the addition of a methyl group to benzene, anisole, toluene, cresol and xylenol respectively were also modelled. The energy barriers for the different reactions pathways in non-catalytic and catalytic decomposition of anisole are shown in Table 1.

In the case of non-catalytic decomposition, the energy barriers of transmethylation changed significantly, depending on the acceptor molecules. This is related to the fact that the substituents on the molecule affect the electron distribution in the aromatic ring, giving rise to the site migration of substituted reactions ${ }^{47}$. Anisole, toluene and phenolic compounds showed energy barrier values between 105.7 and $121.1 \mathrm{kcal} / \mathrm{mol}$ in the non-catalytic transmethylation (Table 1), and the energy barrier for the methyl transfer to benzene in the non-catalytic reaction was the highest for $126.4 \mathrm{kcal} / \mathrm{mol}$.

It is found the molecules containing branch chain substituents, especially oxygen-rich chains such as hydroxy and methoxy functional groups, are more readily to accept methyl radicals. 
231 The branch chains may have impact on the $\pi$-bond of the benzene ring, making the ring more

232 susceptible to methyl attack especially at the ortho- and para-positions, while the benzene

233 ring without branch chains may have smaller electron density, so that is more stable to radical

234 attack $^{48}$.

235 It was observed that transmethylation to phenol and o-cresol exhibited intrinsic preference in

236 the ortho- and para-positions, which is in line with the results from the Fukui analyses for

237 electrophilic attack to phenol molecule (Fig S3(b)). On the other hand, toluene and anisole

238 showed moderate difference (within $4.1 \mathrm{kcal} / \mathrm{mol}$ ) in position preference for non-catalytic

239 transmethylation. This is because the free pair of electrons in the oxygen of the hydroxyl

240 group are more likely to move to the ring, and consequently affect the ring property; while less

241 electron migration and less impact onto the ring occurs with the methyl group attached either

242 directly to the ring (in the case of toluene) or to the oxygen (in the case of anisole) ${ }^{49}$.

243 Table 1. Energy barrier for the different reaction pathways of transmethylation in non-catalytic

244 and catalytic decomposition of anisole

\begin{tabular}{|c|c|c|c|c|c|c|}
\hline \multirow{3}{*}{ Reactant } & \multirow{3}{*}{ Via } & \multirow{3}{*}{ Product } & \multirow{3}{*}{ Orientation } & \multicolumn{3}{|c|}{ Energy Barrier (kcal/mol) } \\
\hline & & & & \multirow{2}{*}{$\begin{array}{c}\text { Non-catalytic } \\
\text { (TS) }\end{array}$} & \multicolumn{2}{|r|}{ Catalytic } \\
\hline & & & & & $\begin{array}{l}\text { Cleavage } \\
\text { (TS1) }\end{array}$ & $\begin{array}{c}\text { Methyl cation transfer } \\
\text { (TS2) }\end{array}$ \\
\hline & & & Ortho & 105.5 & & 60.7 \\
\hline & Phenol & Cresol & Meta & 118.0 & & 67.2 \\
\hline & & & Para & 107.3 & & 66.1 \\
\hline & & & Ortho & 107.2 & & 60.4 \\
\hline & o-Cresol & Xylenol & Meta & 121.1 & & 61.8 \\
\hline & & & Para & 107.0 & & 54.1 \\
\hline \multirow[t]{7}{*}{ Anisole } & & & & & 66.4 & \\
\hline & $\begin{array}{l}2,4- \\
\text { Xylenol }\end{array}$ & $\begin{array}{l}2,4,6- \\
\text { Phenol }\end{array}$ & Ortho & 114.3 & & 60.4 \\
\hline & $\begin{array}{l}2,6- \\
\text { Xylenol }\end{array}$ & $\begin{array}{l}2,3,6- \\
\text { Phenol }\end{array}$ & Meta & 110.0 & & 59.9 \\
\hline & Benzene & Toluene & - & 126.4 & & 73.5 \\
\hline & & & Ortho & 108.1 & & 71.2 \\
\hline & Toluene & Xylene & & & & \\
\hline & & & Meta & 112.2 & & 68.3 \\
\hline
\end{tabular}




\begin{tabular}{|c|c|c|c|c|}
\hline & & Para & 109.5 & 70.8 \\
\hline \multirow{3}{*}{ Anisole } & \multirow{3}{*}{$\begin{array}{l}\text { Methyl- } \\
\text { anisole }\end{array}$} & Ortho & 106.9 & 63.3 \\
\hline & & Meta & 105.7 & 67.0 \\
\hline & & Para & 108.3 & 71.7 \\
\hline
\end{tabular}

245 In the case of catalytic reactions, the presence of the acid catalyst decreased notably the 246 energy barrier values, exhibiting a big influence on promoting transmethylation. The 247 decreases in the energy barrier was observed range from $36.6 \mathrm{kcal} / \mathrm{mol}$ (transmethylation to 248 para position of anisole) to $59.3 \mathrm{kcal} / \mathrm{mol}$ (transmethylation to meta position of o-cresol). The 249 transmethylation to benzene is found had the highest energy barrier for $73.5 \mathrm{kcal} / \mathrm{mol}$, even 250 though it has been diminished by roughly $53 \mathrm{kcal} / \mathrm{mol}$ compared to the non-catalytic process, 251 this indicates the stability of the benzene ring to electrophilic attack compared to other branch 252 chain contained compounds. In the case of the transmethylation to toluene, the model also 253 predicted a decrease in the energy barrier value for each of the position transfers when using 254 a catalyst (ranging between $68.3 \mathrm{kcal} / \mathrm{mol}$ and $71.2 \mathrm{kcal} / \mathrm{mol}$ ), but the predicted energy barriers 255 are higher than those for most oxygen contained compounds, regardless of the position 256 transfer. It is also noted that transmethylation to anisole at the ortho-position to produce 257 methyl-anisole exhibited a similar energy barrier value to other phenolic intermediate 258 compounds $(63.3 \mathrm{kcal} / \mathrm{mol})$. This result suggests that the presence of sole methyl group 259 attached to the aromatic ring has limited effect on the molecules to accept electrophilic 260 substitution by methyl carbocation, this may attribute to the lower electronegativity of the 261 methyl group than that of the oxygen contained functional groups ${ }^{50}$. In other words, hydroxyl 262 and methoxyl groups are the most likely ones to promote the reactivity of the aromatic ring, 263 followed by methyl group. Benzene molecule itself is the least reactive compound among the 264 evaluated molecules in the catalytic transmethylation over the Brønsted acid sites. At a 265 macroscopic level, it can be inferred that in the catalytic decomposition of anisole, majority of 266 toluene and xylene are probably produced from the deoxygenation of cresols and xylenols, 267 rather than from the transmethylation to benzene over the Brønsted acid sites.

268 Compared to AHs, methyl phenolic compounds, i.e. phenol, cresol and xylenol, are found to 269 be prone to accept electrophilic substitution at all positions, even though a slight preference 270 (values difference lower than $8 \mathrm{kcal} / \mathrm{mol}$ ) for ortho- and para-positions were observed in the 
271 case of phenol and cresol. Among all the evaluated compounds, these molecules accept 272 methyl carbocation at the lowest energy barrier values. Transmethylation for cresol into 273 xylenol presented energy barriers ranging from $54.1 \mathrm{kcal} / \mathrm{mol}$ ( $p$-position transfer) to 61.8 $274 \mathrm{kcal} / \mathrm{mol}$ (m-position transfer). Transmethylation to convert xylenol into 2,3,6-methyl phenol 275 and 2,4,6-methyl phenol exhibited similar energy barriers at around $60 \mathrm{kcal} / \mathrm{mol}$. These 276 results well illustrate the experimental results during catalytic decomposition of anisole in 277 which the abundant production of multi-methyl phenolic compounds and the typical position 278 preference was observed ${ }^{42}$. The formation of these multi-methyl phenolic compounds from 279 anisole depends on the initial formation of cresol.

\section{CONCLUSION}

This work presents the DFT modelling of the transmethylation as the primary reaction taking place in both non-catalytic and catalytic anisole decomposition. Methyl radical cleavage led to the transmethylation process in non-catalytic transmethylation, which primarily took place with the methyl free radical transfer. In catalytic transmethylation, reactants interacted with the Brønsted acid sites present in the catalyst. The catalytic transmethylation was initiated by the Brønsted acid proton electrophilic attack at the oxygen atom of anisole, followed by a carbocation substitution. A dual electrophilic attack mechanism was proposed for the catalytic transmethylation. Transmethylation reactions modelling, based on the proposed mechanism, proved that the Brønsted acid catalyst could significantly lower the reaction energy barrier for all reactant compounds investigated due to changes in the reaction pathways. Most of the energy barriers for the evaluated transmethylation reactions decreased more than $40 \mathrm{kcal} / \mathrm{mol}$ when considering the catalytic effect, the highest decrease being observed in the case of ocresol (around $60 \mathrm{kcal} / \mathrm{mol})$. Furthermore, both non-catalytic and catalytic transmethylation exhibited target molecule preference, depending on the original substituents of the acceptor, and transmethylation to most compounds showed preference for the ortho- and parapositions. Non-catalytic transmethylation to compounds with oxygen-rich substituents generally showed lower energy barriers. In the catalytic decomposition of anisole, the presence of oxygen-rich substituents also enhanced the reactivity of the ring, especially for phenolic compounds at the ortho- and para-positions. The lowest energy barrier was 
300

301

302

303

304

305

306

307

308

309

310

311

312

313

314

315

316

31

318

319

320

321

322

32

324

325

observed in the case of transmethylation towards the para-position of the cresol molecule $(54.1 \mathrm{kcal} / \mathrm{mol})$.

\section{AUTHOR INFORMATION}

\section{Corresponding Author}

D.S.: 101011398@seu.edu.cn

Author Contributions

All authors have given approval to the final version of the manuscript.

\section{Notes}

The authors declare no competing financial interest.

\section{ACKNOWLEDGEMENT}

The authors would like to acknowledge financial support from the National Natural Science Foundation of China (project references: 51476034 and 51628601), Natural Science Foundation of Jiangsu Province (project reference: BK20161423), and the FP7 Marie Curie iComFluid (project reference: 312261).

\section{REFERENCES}

1 W. Boerjan, J. Ralph and M. Baucher, Annu. Rev. Plant Biol., 2003, 54, 519-546.

2 C. S. Lancefield and N. J. Westwood, Green Chem., 2015, 17, 4980-4990.

3 A. V. Bridgwater, Biomass and Bioenergy, 2012, 38, 68-94.

4 A. V. Bridgwater and G. V. C. Peacocke, Renew. Sustain. energy Rev., 2000, 4, 1-73.

5 K. A. Jung, S. H. Woo, S.-R. Lim and J. M. Park, Chem. Eng. J., 2015, 259, 107-116.

6 L. Zhang, R. Liu, R. Yin and Y. Mei, Renew. Sustain. Energy Rev., 2013, 24, 66-72.

7 C. Liu, H. Wang, A. M. Karim, J. Sun, Y. Wang, M. Karim Ayman, J. Sun and Y. Wang, Chem. Soc. Rev., 2014, 43, 7594-7623.

8 S. Vichaphund, D. Aht-ong, V. Sricharoenchaikul and D. Atong, Renew. Energy, 2014, $65,70-77$.

9 C. Mukarakate, J. D. McBrayer, T. J. Evans, S. Budhi, D. J. Robichaud, K. lisa, J. ten 

4227.

10 C. Mukarakate, X. Zhang, A. R. Stanton, D. J. Robichaud, P. N. Ciesielski, K. Malhotra, B. S. Donohoe, E. Gjersing, R. J. Evans, D. S. Heroux, R. Richards, K. lisa and M. R. Nimlos, Green Chem., 2014, 16, 1444. Prins, J. Anal. Appl. Pyrolysis, 2013, 103, 343-351. 101, 6136-6146.

Q. Meng, H. Fan, H. Liu, H. Zhou, Z. He, Z. Jiang, T. Wu and B. Han, ChemCatChem, $2015,7,2831-2835$.

T. Prasomsri, A. T. To, S. Crossley, W. E. Alvarez and D. E. Resasco, Appl. Catal. B Environ., 2011, 106, 204-211.

K. Wang, X. Dong, Z. Chen, Y. He, Y. Xu and Z. Liu, Microporous Mesoporous Mater., $2014,185,61-65$.

J. Cornella, E. Gómez-Bengoa and R. Martin, J. Am. Chem. Soc., 2013, 135, 19972009.

C. Mackie, R. Doolan and F. Nelson, J. Phys. Chem. C, 1989, 93, 664-670.

M. E. Sad, C. L. Padró and C. R. Apesteguía, Catal. Today, 2008, 133-135, 720-728.

J. Xu, A. Z. Yan and Q. H. Xu, Appl. Catal., 1999, 10, 983-986. Commun., 2004, 94, 119-123. Maselli, S. Passeri and I. Rossetti, J. Catal., 2007, 245, 285-300.

$35123 \quad$ K. G. Bhattacharyya, A. K. Talukdar, P. Das and S. Sivasanker, J. Mol. Catal. A 

72.

25 X. Zhu, R. G. Mallinson and D. E. Resasco, Appl. Catal. A Gen., 2010, 379, 172-181.

35626 N. Ballarini, F. Cavani, L. Maselli, A. Montaletti, S. Passeri, D. Scagliarini, C. Flego and C. Perego, J. Catal., 2007, 251, 423-436.

J. H. Baraban, P. B. Changala, G. C. Mellau, J. F. Stanton, A. J. Merer and R. W. Field, Science (80-. )., 2015, 350, 1338-1342. 2239. 986.

Z. Geng, M. Zhang and Y. Yu, Fuel, 2012, 93, 92-98.

Y. Huang, X. Dong, M. Li, Y. Yu, J. Gao, Y. Zheng, G. B. Fitzgerald, J. de Joannis, Y. Catal. Sci. Technol., 2015, 5, 1093-1105.

Y. Huang, X. Dong, M. Li, M. Zhang and Y. Yu, RSC Adv., 2014, 4, 14573. Podkolzin, J. Phys. Chem. C, 2014, 118, 4670-4679. Zhao, Z. S. Yang and X. Fan, Fuel, 2014, 120, 158-162.

B. Delley, J. Chem. Phys., 1990, 92, 508-517.

B. Delley, J. Chem. Phys., 2000, 113, 7756. mesoporous Mater., 2004, 71, 51-56.

B. Kalita and R. C. Deka, Eur. Phys. J. D, 2009, 53, 51-58. 
$38041 \quad$ F. L. Hirshfeld, Theor. Chim. Acta, 1977, 44, 129-138.

38142 J. Zhang, B. Fidalgo, D. Shen, R. Xiao and S. Gu, J. Anal. Appl. Pyrolysis, 2016, 122, $382 \quad 323-331$.

38343 J. F. Haw, B. R. Richardson, I. S. Oshiro, N. D. Lazo and J. a. Speed, J. Am. Chem. 384 Soc., 1989, 111, 2052-2058.

$38544 \quad$ B. R. Richardson, N. D. Lazo, P. D. Schettler, J. L. White and J. F. Haw, J. Am. Chem. 386 Soc., 1990, 112, 2886-2891.

38745 E. J. Munson, T. Xu and J. F. Haw, J. Chem. Soc. Chem. Commun., 1993, 75-76.

$38846 \quad$ E. J. M. and J. F. H. Teng Xu, Jinhua Zhang, Chem. Commun., 1994, 2733-2735.

$38947 \quad$ F. L. Lambert, J. Chem. Educ., 1958, 35, 342-343.

39048 T. Phuong, J. Catal., 1986, 102, 456-459.

39149 X. Zhu, L. L. Lobban, R. G. Mallinson and D. E. Resasco, J. Catal., 2011, 281, 21-29.

39250 F. De Proft, W. Langenaeker and P. Geerlings, J. Phys. Chem., 1993, 97, 1826-1831. 


\section{Supplementary Information}

Table S1: Unique imaginary frequency identified for each transition state of the reactions for both non-catalytic and catalytic transmethylation

\begin{tabular}{|c|c|c|c|c|c|c|}
\hline \multirow{2}{*}{ Reactant } & \multirow{2}{*}{ Via } & \multirow{2}{*}{ Product } & \multirow{2}{*}{ Orientation } & \multicolumn{3}{|c|}{ Imaginary frequency (Frequency $(1 / \mathrm{cm}) ;$ Intensity $(\mathrm{km} / \mathrm{mol}))$} \\
\hline & & & & Non-catalytic (TS) & \multicolumn{2}{|l|}{ Catalytic } \\
\hline \multirow{11}{*}{ anisole } & \multirow{3}{*}{ phenol } & \multirow{3}{*}{ Cresol } & Ortho & $-15.49 / 0.03$ & & $-352.36 / 6.86$ \\
\hline & & & Meta & $-11.96 / 0.14$ & & $-285.63 / 7.12$ \\
\hline & & & Para & $-10.15 / 0.11$ & & $-435.58 / 5.90$ \\
\hline & \multirow[t]{2}{*}{ o-cresol } & \multirow[t]{2}{*}{ Xylenol } & Meta & $-144.6 / 1.40$ & & $-311.78 / 158.17$ \\
\hline & & & Para & $-270.32 / 163.89$ & & $-343.56 / 192.81$ \\
\hline & 2,4-xylenol & 2,4,6-phenol & Ortho & $-237.38 / 453.09$ & & $-171.58 / 6.64$ \\
\hline & 2,6-xylenol & 2,3,6-phenol & Meta & $-229.42 / 129.61$ & $-331.54 / 99.74$ & $-511.45 / 499.08$ \\
\hline & \multirow[t]{2}{*}{ benzene } & \multirow[t]{2}{*}{ Toluene } & - & $-686.39 / 37.85$ & & $-233.06 / 16.67$ \\
\hline & & & Ortho & $-244.71 / 129.42$ & & $-138.44 / 101.67$ \\
\hline & \multirow[t]{2}{*}{ anisole } & \multirow[t]{2}{*}{ methyl-anisole } & Meta & $-6823.26 / 7.10$ & & $-313.60 / 67.33$ \\
\hline & & & Para & $-267.68 / 159.39$ & & $-309.34 / 2.79$ \\
\hline
\end{tabular}


Fig S2. (a) Mulliken bond order of the anisole molecule for the transmethylation reaction; (b) Fukui indices of anisole atoms under electrophilic attack (Fukui (-)). Isovalue 0.035. Atoms are colored as follows: carbon atom (grey), hydrogen atom (white) and oxygen atom (red)

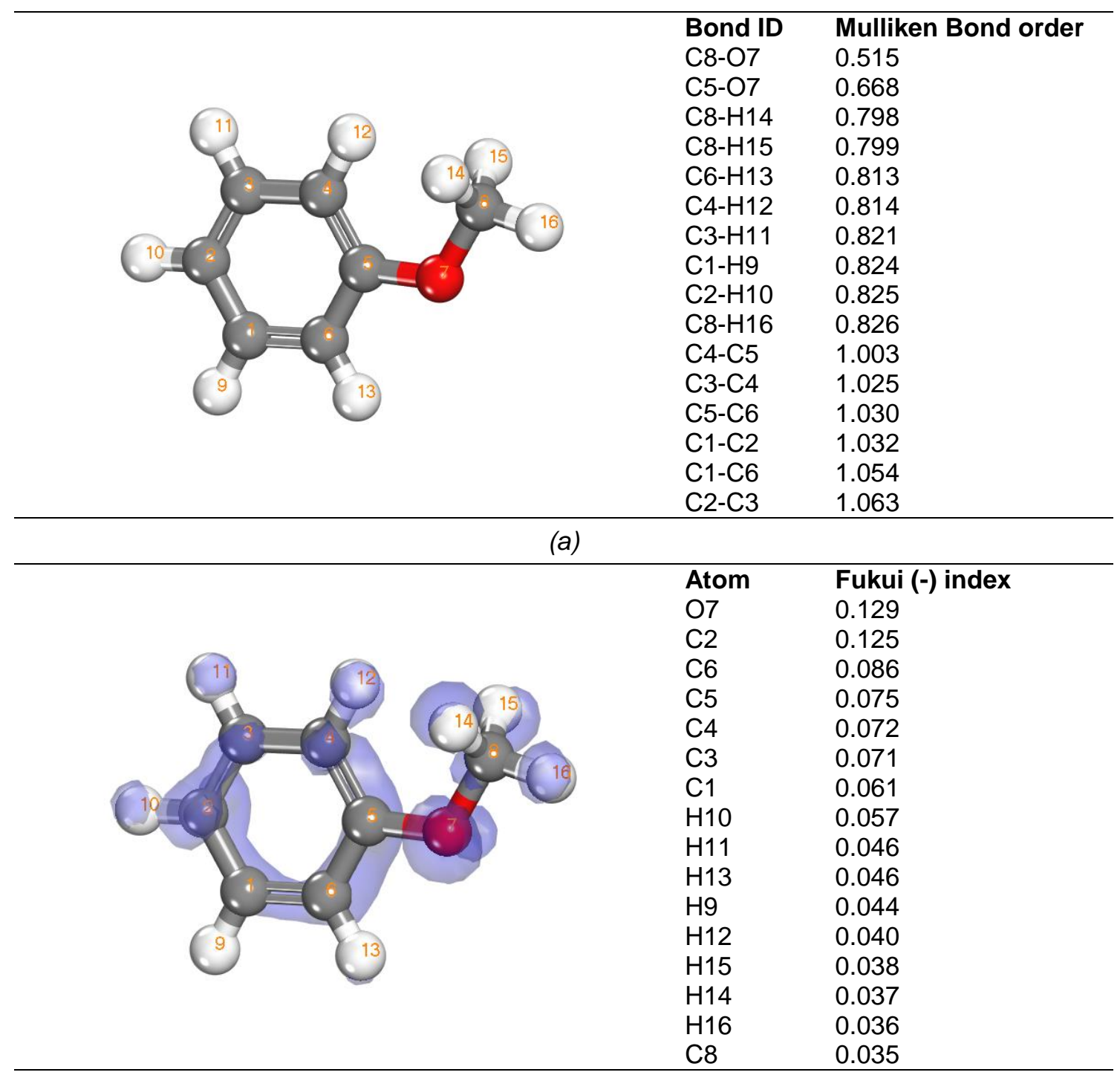

(b)

Fig S3. Fukui indices for (a) radical attack on phenol molecule (Fukui (0)), and (b) electrophilic attack on phenol molecule (Fukui (-)). Isovalue 0.035. Atoms are colored as follows: carbon atom (grey), and hydrogen atom (white) and oxygen atom (red)

\begin{tabular}{|c|c|c|}
\hline 0 & $\begin{array}{l}\text { Atom } \\
\text { C4 } \\
\text { O7 } \\
\text { C2 } \\
\text { C6 } \\
\text { C1 } \\
\text { C3 } \\
\text { C5 } \\
\text { H8 } \\
\text { H10 } \\
\text { H11 } \\
\text { H9 } \\
\text { H12 } \\
\text { H13 }\end{array}$ & $\begin{array}{l}\text { Fukui (0) index } \\
0.105 \\
0.103 \\
0.102 \\
0.100 \\
0.099 \\
0.095 \\
0.073 \\
0.057 \\
0.056 \\
0.056 \\
0.055 \\
0.055 \\
0.044\end{array}$ \\
\hline
\end{tabular}


(a)

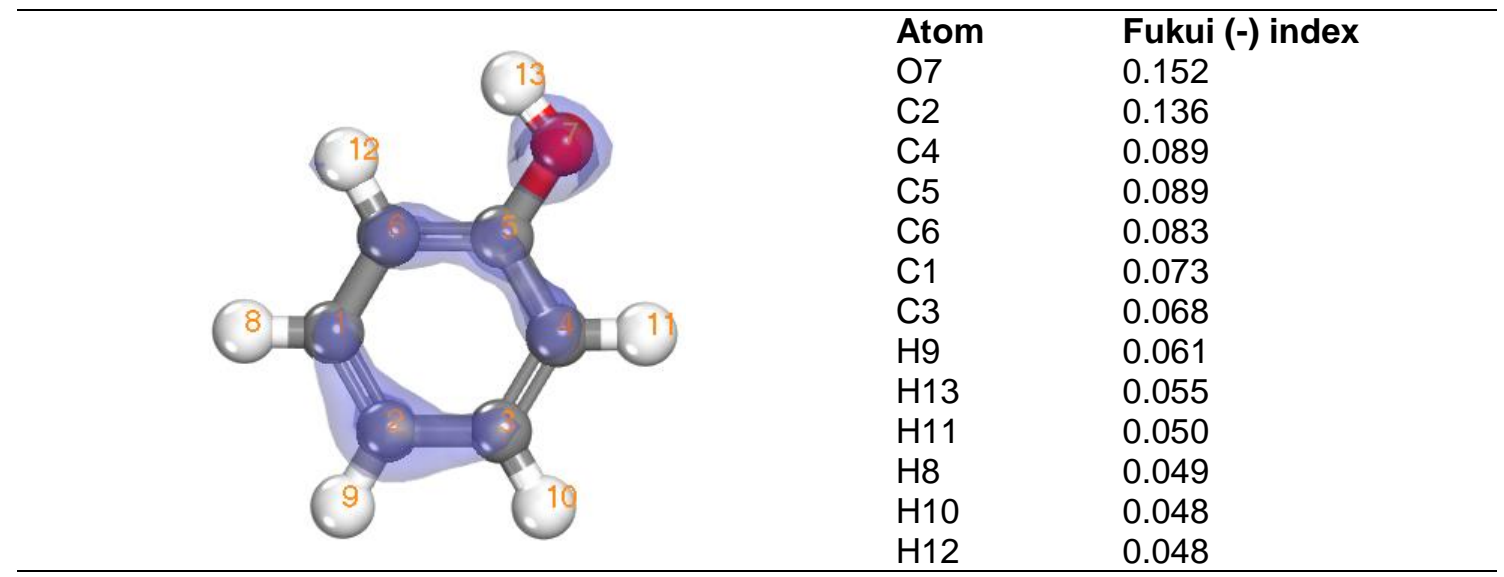

(b) 